\title{
The Intergovernmental Science-Policy Platform on Biodiversity and Ecosystem Services (IPBES): getting involved
}

\author{
Dirk S. Schmeller ${ }^{1,2}$ (D) Jari Niemelä ${ }^{3}$ Peter Bridgewater ${ }^{4,5}$
}

Received: 24 March 2017 / Accepted: 24 April 2017/Published online: 5 May 2017

(C) Springer Science+Business Media Dordrecht 2017

\begin{abstract}
The Intergovernmental Science-Policy Platform for Biodiversity and Ecosystem Services (IPBES) held its 5th plenary session in Bonn during March 2017. After last year's pollinator assessment, the biodiversity assessments currently being undertaken are shortly to be available for peer review. The scientific community can play an important role in both conducting assessments and in the peer-review process. Independent scientists can contribute to ensure that these assessments are comprehensive with respect to the current state and future trends of biodiversity and the ecosystem services. We outline possibilities for deeper involvement of the scientific community in the IPBES process and draw attention to upcoming reviews in 2017.
\end{abstract}

Keywords Convention on biological diversity $\cdot$ Science-policy $\cdot$ Biodiversity assessments · IPBES

Communicated by David Hawksworth.

Dirk S. Schmeller

ds@die-schmellers.de

1 Department of Conservation Biology, Helmholtz Center for Environmental Research - UFZ, Permoserstrasse 15, 04318 Leipzig, Germany

2 EcoLab (Laboratoire Ecologie Fonctionnelle et Environnement), Université de Toulouse, UPS, INPT, Toulouse, France

3 Department of Environmental Sciences, University of Helsinki, PO Box 65, 00014 Helsinki, Finland

4 Institute for Applied Ecology, University of Canberra, Locked Bag 1, Canberra, ACT 2601, Australia

5 School of Nature Conservation, Beijing Forestry University, Qinghuadonglu No. 35, Haidian District, Beijing 100083, China 


\section{Introduction}

The Intergovernmental Science-Policy Platform for Biodiversity and Ecosystem Services (IPBES-pronounced ip-bes-) was fully operationalized in 2011 by the United Nations Environment Programme (UNEP) based on Resolution 65/162 of the United Nations General Assembly. Currently, 126 countries are members of IPBES. Compared to the IPCC, the task of IPBES is much more complex and perhaps even more important for the future of people and nature. IPBES is assessing the human impact on biodiversity and ecosystem services; assembling existing data on biodiversity and ecosystem services to generate new insights relevant for policy; promoting a continuous dialogue between science, knowledge holders and policy, and detecting and filling gaps in the global knowledge base on biodiversity and ecosystem services (Bridgewater 2017; Schmeller and Bridgewater 2016). At the meeting conceptualizing IPBES in Busan, Republic of Korea in 2010 (http://www.ipbes.net/plenary/busan-2010-3rd-meeting-ipbes), four key work areas were foreseen. These areas are overseen by a Multidisciplinary Expert Panel (MEP), and discussed annually through a plenary meeting of the Nations who are members of the Platform. The areas comprise:

(i) identifying and prioritizing key scientific information needed for policymakers at appropriate scales and catalyze efforts to generate new knowledge;

(ii) performing regular and timely assessments of knowledge on biodiversity and ecosystem services and their interlinkages, and maintain a catalogue of relevant assessments, identify the need for regional and subregional assessments and help to catalyze support for subregional and national assessments;

(iii) supporting policy formulation and implementation by identifying policy-relevant tools and methodologies;

(iv) prioritizing key capacity-building needs to improve the science-policy interface at appropriate levels.

The first substantive deliverable under the Platform was an assessment on pollination and pollinators (Potts et al. 2016), which was accepted during the 4th Plenary in Kuala Lumpur in 2016 (Opgenoorth and Hotes 2016; Schmeller and Bridgewater 2016). Importantly, a summary for policy makers was also approved by Plenary 4 . While the pollination report was an important achievement, and has stimulated some follow-up actions and initiatives (http://www.ipbes.net/work-programme/pollination), it has been a first step, and in some ways could be seen as test run of IPBES's assessment procedures. In particular, the key messages were recognized by the Convention on Biological Diversity in a decision (CBD/COP/DEC/XIII/15) at its 13th meeting in Cancun, México, 2016. This stimulated a limited number of countries to form a "coalition of the willing" to work on some of the key problems identified in the assessment.

During the latest plenary meeting in Bonn (Plenary 5), March 2017, progress on regional assessments and the land degradation assessment were discussed, and the slower progress on the global assessment noted. This global assessment, which will build on the regional assessments, will be the successor to the Millennium Ecosystem Assessment (2005) and of outstanding importance for the biodiversity research community and global policy makers dealing with biodiversity issues. However, the regional assessments will deliver their products only in 2018, when Plenary6 will receive them, discuss them and decide to approve them as appropriate. The global assessment is scheduled for completion, and will be due for approval, at the 7th IPBES plenary in 2019. One important issue 
resolved at the March 2017 plenary was the approach to indigenous and local knowledge for all the Platform's deliverables. Adoption of this approach means that a wider range of worldviews will be available to help produce deliverables which fully comprehend "nature's contributions to people". Much intersessional work on the topic of nature's contributions to people has been, and will continue to be, undertaken (Pascual et al. 2017) and will be an important discussion topic at IPBES6.

Plenary 5 also noted scoping documents for invasive species, and the diverse conceptualization of values, and approved the scoping report for a thematic assessment on sustainable use of biodiversity. Discussions on these currently 'pending' assessments of the 1st IPBES work program resulted in them being held in abeyance, and deliberations centered around budgetary issues. Unlike international conventions and agreements, such as the CBD, IPBES has no fixed scale of contributions from member states. This has led to a situation where the Platform has funding to achieve its work program in 2017, but appears to be in difficulty in later years, leaving some of the ongoing assessment with uncertainty about timely competition. While this will hopefully change, the Plenary set budgets reflect currently known funding, which may prevent the launch of the remaining assessments of the 1st work program and other activities in the 2018-2019 period. For instance, the three 'pending' assessments (invasive species, conceptualization of values, and sustainable use) will be postponed and their launch will be decided at the 6th plenary to be held in Medellín, Columbia in March 2018. Although not directly related to the strict budgetary constraint, the Platform will undergo a review in 2018. This review will have two parts, an internal review which will feed its conclusions to an independent external review. The external review will evaluate the effectiveness of IPBES as a science-policy interface, analyse the Platform regarding its effectiveness and efficiency and, where possible, relevance. The review will measure effectiveness of the programme and administrative arrangements against IPBES' current objectives, operating principles, and the four functions agreed at the Busan meeting.

The scientific community has several ways to contribute to the different assessments; as (1) member of the Multidisciplinary Expert Panel (MEP) of IPBES, (2) nominated expert in the assessments, (3) expert reviewer of the assessment, and (4) nominated reviewer of the final assessment draft. IPBES thrives for balance in gender, expertise, and by UN region in each of these panels and groups. However, currently biases still exist towards male experts, ecological expertise, and developed countries, while this has improved over time (Hochkirch et al. 2014). For the readership of Biodiversity and Conservation the most important ways to contribute to IPBES assessments are as a nominated expert or expert reviewer. As a nominated expert, one can contribute to assessments as (1) (co)chair, overseeing the preparation of assessment reports and ensuring a high scientific standard at completion, as (2) coordinating lead author, coordinating major sections and/or chapters in regard to comprehensiveness, style scientific standard, and cross-cutting issues of significance across several sections, (3) lead author, producing designated sections or parts of chapters by synthesizing information material from available in scientific literature and by coordinating contributing authors, and (4) as contributing author, preparing technical information provided to lead authors of the respective section or chapter. To become an expert governments nominate them based on suggestions from research institutions, which themselves may have a process in place to select the most suitable experts to be suggested to the national government. From the national nominee list, the MEP then selects experts in regard to expertise, gender, and origin to guarantee a balanced group of experts. A maximum of $80 \%$ of experts in an assessment are recruited following this procedure. An additional $20 \%$ of experts can be suggested to the MEP by observer institutions or other 
stakeholder groups to fill gaps, to add expertise, and to reduce biases in the different assessments.

A much less restrictive but equally important way to contribute to assessments is the online consultation process of drafts of assessment reports to which everyone with relevant expertise can contribute, following registration with IPBES. The chairs and coordinating lead authors of the assessments must take into consideration each of the comments made and may need to adapt the chapter and section accordingly. This is a considerable workload. For instance, the 1st draft of the thematic assessment of pollinators, pollination and food production (http://www.ipbes.net/work-programme/pollination) received 5211 comments by 142 expert reviewers. The 2 nd draft received almost as many comments (5166 comments from 130 experts and 8 governments). It is of importance to the process that the scientific community engages in the reviews of the various assessment drafts and adds their expertise and points-of-view (Lundquist et al. 2015). The broad scale of the IPBES assessments demands a large variety of experts from across the world, realms, cultural background, and scientific fields. Hence, the expert opinion of each of the authors and readers of Biodiversity and Conservation is very much welcomed during this review stage.

The next external review rounds are on the second order drafts of the thematic assessment report on land degradation and restoration, and of the four regional assessments (Africa, Asia-Pacific, Americas, and Europe and Central Asia) on biodiversity and ecosystem services, as well as the first order drafts of their Summaries for Policymakers. The review period will be over 8 weeks in May to June 2017 (Africa, Asia-Pacific, Europe and Central Asia) and June to July 2017 (Americas). Please check the IPBES website (ipbes.net) for instructions and the exact timetable.

Finally, IPBES allows observers at their plenaries and considers them an essential part of the overall process. The only prerequisite for participation is confirmed registration with the IPBES member database. Currently, the scientific community is organized in the openended IPBES stakeholder network, which is open to any IPBES registered individual, institution, authority and local government. Before plenaries, one or more stakeholder days are held to allow discussion of IPBES documents and procedures and the development of recommendations to the secretariat and MEP. During the plenaries, the participating observers hold their own consultation meetings, participate in contact groups (while they are allowed to speak only with the invitation of the chair) and have the possibility to share their opinion on documents and decisions under discussion with member state delegations. These are also important means to contribute to the IPBES process.

We encourage our readership to inform themselves on IPBES, engage with the processes and to promote IPBES further in the scientific and non-scientific communities.

\section{References}

Bridgewater P (2017) The intergovernmental platform for biodiversity and ecosystem services (IPBES) — a role for heritage? Int J Herit Stud 23:65-73. doi:10.1080/13527258.2016.1232657

Hochkirch A, McGowan PJK, van der Sluijs J (2014) Publishing: biodiversity reports need author rules. Nature 516:170. doi:10.1038/516170c

Lundquist CJ, Báldi A, Dieterich M, Gracey K, Kovacs EK, Schleicher J, Skorin T, Sterling E, Jonsson BG (2015) Engaging the conservation community in the IPBES process. Conserv Biol 29:1493-1495

Millenium Ecosystem Assessment (2005) Ecosystems and human well-being: wetlands and water. World Resources Institute, Washington, DC

Opgenoorth L, Hotes S (2016) IPBES is in the books: Pollination and scenario assessments are the first two steps to guiding policy makers in the global biodiversity crisis. Front Biogeogr 8.1: e30404 
Pascual U, Balvanera P, Díaz S, Pataki G, Roth E, Stenseke M, Watson RT, Başak Dessane E, Islar M, Kelemen E, Maris V, Quaas M, Subramanian SM, Wittmer H, Adlan A, Ahn S, Al-Hafedh YS, Amankwah E, Asah ST, Berry P, Bilgin A, Breslow SJ, Bullock C, Cáceres D, Daly-Hassen H, Figueroa E, Golden CD, Gómez-Baggethun E, González-Jiménez D, Houdet J, Keune H, Kumar R, Ma K, May PH, Mead A, O'Farrell P, Pandit R, Pengue W, Pichis-Madruga R, Popa F, Preston S, PachecoBalanza D, Saarikoski H, Strassburg BB, van den Belt M, Verma M, Wickson F, Yagi N (2017) Valuing nature's contributions to people: the IPBES approach. Curr Opin Environ Sustain 26-27:7-16. doi:10.1016/j.cosust.2016.12.006

Potts SG, Imperatriz-Fonseca VL, Ngo HT, Biesmeijer JC, Breeze TD, Dicks LV, Garibaldi LA, Hill R, Settele J, Vanbergen AJ (2016) Summary for policymakers of the assessment report of the Intergovernmental Science-Policy Platform on Biodiversity and Ecosystem Services on pollinators, pollination and food production. Report. Intergovernmental Science-Policy Platform on Biodiversity and Ecosystem Services, Bonn, Germany. pp 36. ISBN 9789280735680

Schmeller DS, Bridgewater P (2016) The intergovernmental platform on biodiversity and ecosystem services (IPBES): progress and next steps. Biodivers Conserv 25:801-805. doi:10.1007/s10531-0161095-9 